\title{
Hydraulic Performance of Drip Emitters under Field Condition
}

\author{
Pankaj Sharma
}

\begin{abstract}
A field study was undertaken to evaluate the performance of on - line non pressure compensating drip emitters of 2, 4 and 8 lph discharge ratings. The system was tested for its uniformity coefficient, emission uniformity, manufacturing coefficient of variation and head discharge relationship. The study revealed that for better discharge of on-line emitters of 2, 4 and 8 lph capacity, optimal pressure of 40, 70 and $100 \mathrm{KPa}$ is required respectively to achieve uniformity coefficient of more than 90\%. In 2, 4 and 8lph capacity emitters, emission was 86.73, 84.37 and 91.6 per cent respectively. Manufacturing coefficient of variation for different emitters having 2, 4 and 8 lph capacity was $0.165,0.171$ and .101 respectively.

For inline emitter of 1.3 lph capacity, optimal pressure $100 \mathrm{kPa}$ is required to achieve uniformity coefficient of $85 \%$ and emission was 85.81 per cent respectively. Manufacturing coefficient of variation for the 1.3lph capacity emitter was .128 respectively.
\end{abstract}

Keywords: Discharge, pressure, irrigation, emitter, manufacturing coefficient of variation, uniformity coefficient.

\section{Introduction}

For achieving high effectiveness of water, use drip irrigation is one of the most appropriate technologies in modern irrigated agriculture with great potential. It also leads itself to easy adoption for chemigation and automation. Drip system permits the controlling of discharge and flexibility in time of water application. It saves water to extent of 30 to 70 per cent without significantly affecting the crop yield (Satpute and Pandey, 1989; and Pandey et al., 2003). Drip irrigation systems are widely used for irrigating orchards, vegetables, spices, cash crops like sugarcane and cotton and the area covered under this system is about 3.5 lakh ha in India (kumar,2001).

In drip irrigation system, water is delivered precisely through the emitters. The capacity of the emitters available in the market varies from 2 to $16 \mathrm{lph}$. These are categorized as pressure and non-pressure compensating. The former show no variation in discharge due to the corresponding change in the pressure head but in the latter the discharge changes with pressure. Little scientific information is available on the flow characteristics of different emitters under operating pressure. Keeping this in view a field test was done to evaluate the hydraulics of on-line, non-pressure compensating emitters of different discharges ratings.

\section{Materials And Methods}

A drip irrigation system was installed in is the demonstration farm of IIT Roorkee(uttarakhand ) located at $29^{0} 50^{\prime} 05.4^{\prime \prime} \mathrm{N}$ latitude and $77^{\circ} 55^{\prime} 17.7^{\prime \prime} \mathrm{E}$ longitude with an altitude of $248 \mathrm{~m}$ above mean sea level.(fig1). The system was tested for its uniformity coefficient, emission uniformity, and manufacturing coefficient of variation. Pressure gauges readings were noted when they attained a constant value .cans was used for discharge collection and the collected water was measured in a measuring cylinder.

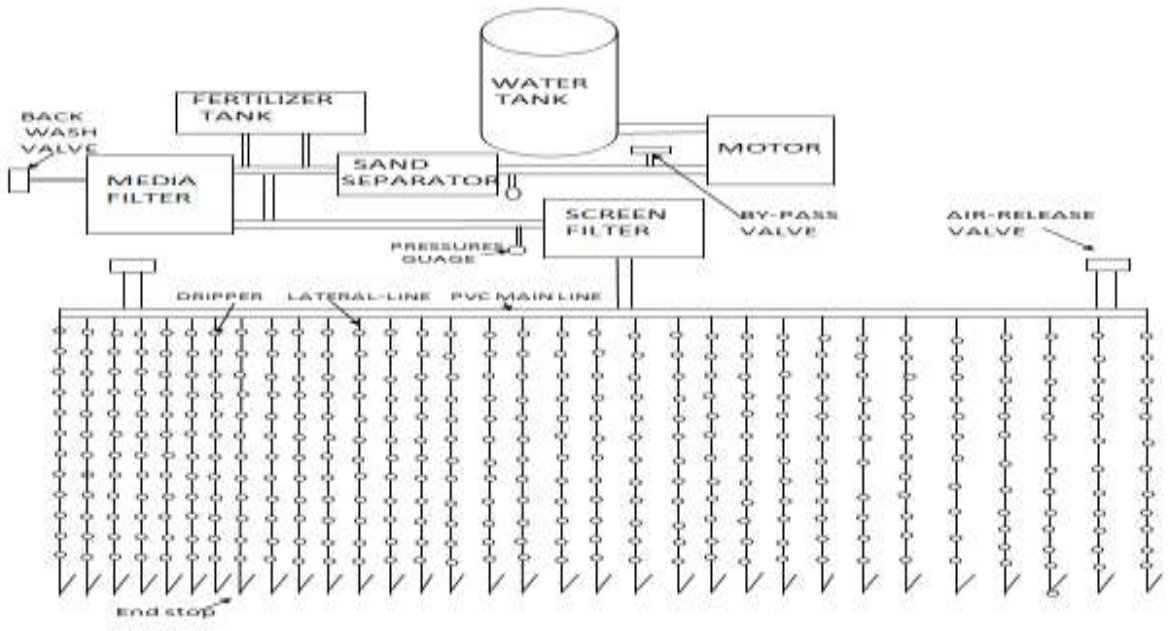

Fig. Experimental of the drip irrigation system layout in the field 


\section{Uniformity coefficient}

\section{Performance Evaluation}

Uniformity coefficients of emitters were tested using the Christiansen's formula(1942). It gives the information that how efficiently water is distributed in the field.

$$
\mathrm{Cu}=1000\left(1-\sum \mathrm{X} / \mathrm{mn}\right)
$$

Where $\mathrm{Cu}=$ coefficient of uniformity

$\mathrm{m}=$ Average value of all observations

$\mathrm{n}=$ Total number of observation points

$\mathrm{X}=$ Numerical deviation of all observation points from the average application rate

\section{Emission uniformity}

The coefficient of variation is defined as the ratio of standard deviations of the discharges (Madramootto, 1988), and is given by

$\mathrm{EU}=100\left[1-1.27 \mathrm{Cv} /\left(\mathrm{n}^{0.5}\right)\right]\left(\mathrm{q}_{\mathrm{min}} / \mathrm{q}_{\mathrm{avg}}\right)$

Where $\mathrm{EU}=$ Emission uniformity

$\mathrm{C}_{\mathrm{V}}=$ Manufacturer's coefficient of variation

$\mathrm{n}=$ Number of emitters per plant for trees and shrubs

$\mathrm{q}_{\min }=$ Minimum emitter discharge rate for the minimum pressure in the section

The emission uniformity of the water application varies with pressure, emitter variation, and number of emitters discharging. For a point source of drip irrigation system installed in uniform topography recommended value of EU ranges from 85-90 \%( ASAE, 1989).

\section{Manufacturing coefficient o variation}

The coefficient of variation $\left(\mathrm{C}_{\mathrm{V}}\right)$ is defined as the ratio of standard deviations of the discharges (Madramootto, 1988). In the lateral design, emitter flow variation is used as a design criterion. The emitter flow variation comprises hydraulic variation and due to manufacturing variation among the emitters. The latter depends on the quality control in production. The unit to unit variation in the emitter flow was expressed by the following relationship:

$\mathrm{C}_{\mathrm{V}}=\mathrm{S} / \mathrm{q}$

Where $C_{V}=$ Manufacturing coefficient of variation

$\mathrm{S}=$ sample standard deviation

$\mathrm{q}=$ Average emission rate of sample

Table 1: Classification of manufacturer's coefficient of variations

\begin{tabular}{|l|l|l|}
\hline Emitter type & $\mathrm{C}_{\mathrm{v}}$ range & Classification \\
\hline Point source & $<0.05$ & Excellent \\
\cline { 2 - 3 } & $0.05-0.07$ & Average \\
\cline { 2 - 3 } & $0.07-0.11$ & Marginal \\
\cline { 2 - 3 } & $0.11-0.15$ & Poor \\
\cline { 2 - 3 } & $>0.15$ & Unacceptable \\
\hline Line source & $<0.10$ & Good \\
\cline { 2 - 3 } & $0.10-0.20$ & Average \\
\cline { 2 - 3 } & $>0.20$ & Marginal to unacceptable \\
\hline
\end{tabular}

\section{Head - discharge relationship}

The head discharge relationships for emitters were expressed by the formula (karmeli, 1977, Wu and Gitlin, 1977)

$$
\mathrm{Q}=\mathrm{K}_{\mathrm{d}} \mathrm{H}^{\mathrm{X}}
$$

Where $\mathrm{Q}=$ Discharge rate of drippers (lph)

$\mathrm{K}_{\mathrm{d}}=$ Discharge coefficient

$\mathrm{H}=$ Pressure Head

$\mathrm{X}=$ Dripper flow exponent 
The value of $\mathrm{X}$ varies from 0 to 1 for wide range of drippers. If $\mathrm{X}$ approaches zero, the drippers are classified as fully pressure compensating and it is, however difficult to achieve in the manufacturing process. If the value of $\mathrm{X}$ lies between 0 to 0.5 , the drippers are called pressure compensating and if $\mathrm{X}$ greater than 0.5 , the drippers are classified as non- pressure compensating (Schwab et al 1993).

\section{Result And Discussions}

Emitter discharge was measured at different operating pressures

Table2. Average discharges of online emitter s under different pressure

\begin{tabular}{|l|l|l|l|}
\hline \multirow{2}{*}{ pressure $(\mathrm{kPa})$} & \multicolumn{3}{|l|}{ Average discharge of emitters } \\
\cline { 2 - 4 } & $\mathbf{2}$ lph & $\mathbf{4 l p h}$ & $\mathbf{8 I p h}$ \\
\hline 20 & 1.79 & 2.85 & 5.4 \\
\hline 30 & 1.91 & 3.025 & 5.55 \\
\hline 40 & 2.078 & 3.47 & 5.924 \\
\hline 60 & 2.1345 & 3.8575 & 6.2975 \\
\hline 70 & 2.414 & 4.0485 & 6.4575 \\
\hline 80 & 2.54 & 4.285 & 7.378 \\
\hline 90 & 2.615 & 4.44 & 7.67 \\
\hline 100 & 2.662 & 4.817 & 8.272 \\
\hline
\end{tabular}

Replicated four times. Data revealed that for a average discharge of $2 \mathrm{lph}$, the emitter discharge varied from 1.79 to $2.66 \mathrm{lph}$. The closest to the average discharge $(2.078 \mathrm{lph})$ was obtained at $40 \mathrm{kPa}$ and the discharge variation was only -------. Similar was the case with the emitters of other discharge ratings (Table2). The variation in the discharge of emitters was within the acceptable limit for 2, 4, and 81ph capacity emitter (wu and Gitlin ,1981).For the better performance, drip emitters of 2, 4 and 8 lph capacity require 40,70 and $100 \mathrm{kPa}$ pressure, respectively.

Data revealed that the uniformity coefficient for 2 lph emitter was greater $70 \%$ in all observation; expect the case of $100 \mathrm{kPa}$. As a sample ,Table 3 gives detailed information for the 2 lph rated discharge emitter .Similarly, in the case of 4 and $8 \mathrm{lph}$ rated emitters, the uniformity coefficient was 70 or higher except some cases . Emission uniformity for all the emitter s are given in Table 4 and all are greater than $60 \%$.

Manufacturing coefficients of variation were $0.651, .171$, and 0.101 for 2,4 and 8 lph drip emitters, respectively. As per ASAE (1989) recommendation, it was concluded that the emitters were of good quality.

Average discharges of Inline emitter at different operating p
\begin{tabular}{|l|l|}
\hline \multicolumn{1}{|c|}{ Pressure } & $\begin{array}{l}\text { Average discharge of } \\
\text { emitters }\end{array}$ \\
\hline 40 & 0.57 \\
\hline 50 & 0.61 \\
\hline 60 & 0.71 \\
\hline 70 & 0.8 \\
\hline 80 & 0.91 \\
\hline 90 & 1.05 \\
\hline 100 & 1.38 \\
\hline 110 & 1.24 \\
\hline
\end{tabular}

Replicated four times. Data revealed that for Average discharge of $1.3 \mathrm{lph}$, the emitter discharge varied from .57 to $1.24 \mathrm{lph}$. The closest to the average discharge $(1.38 \mathrm{lph})$ was obtained at $100 \mathrm{kPa}$. Data revealed that the uniformity coefficient for $1.3 \mathrm{lph}$ emitter was greater $70 \%$ in all observation expect the case of 40 and $50 \mathrm{kPa}$. Manufacturing coefficients of variation is .128 for $1.3 \mathrm{lph}$ drip emitters, respectively. As per ASAE (1989) recommendation, it was concluded that the emitters were of good quality 
Table3a: Uniformity coefficient of $2 \mathrm{lph}$

\begin{tabular}{|l|l|l|l|l|l|l|l|}
\hline \multirow{2}{*}{$\begin{array}{l}\text { pressure } \\
(\mathrm{kPa})\end{array}$} & \multicolumn{7}{|c|}{ Uniformity coefficient $(\mathrm{Cu}) \%$} \\
\cline { 2 - 9 } & 1 & 2 & 3 & 4 & Min & Max & Average \\
\hline 20 & 89 & 80 & 85 & 84 & 80 & 89 & 84.5 \\
\hline 30 & 90.5 & 79.5 & 85.5 & 85 & 79.5 & 90.5 & 85 \\
\hline 40 & 90.25 & 98 & 97 & 91.25 & 90.25 & 98 & 94.13 \\
\hline 60 & 89 & 2.45 & 87.45 & 94 & 87.45 & 94 & 90.73 \\
\hline 70 & 75.5 & 83.1 & 69.25 & 91.85 & 69.25 & 91.85 & 80.55 \\
\hline 80 & 61.5 & 84.5 & 63 & 83 & 61.5 & 84.5 & 73 \\
\hline 90 & 79.75 & 72.75 & 74.5 & 64 & 64 & 79.75 & 71.88 \\
\hline 100 & 65 & 68.65 & 68.4 & 65.25 & 65 & 68.65 & 66.83 \\
\hline
\end{tabular}

Table3b:Uniformity coefficient of 4lph

\begin{tabular}{|l|l|l|l|l|l|l|l|}
\hline \multirow{2}{*}{$\begin{array}{l}\text { Pressure } \\
(\mathrm{kPa})\end{array}$} & \multicolumn{7}{|c|}{ Uniformity coefficient $(\mathrm{Cu}) \%$} \\
\cline { 2 - 8 } & 1 & 2 & 3 & 4 & \multicolumn{1}{c|}{ Min } & Max & Average \\
\hline 20 & 65 & 77.5 & 60 & 70 & 60 & 77.5 & 68.75 \\
\hline 30 & 80.25 & 71 & 70.25 & 81 & 70.25 & 81 & 75.63 \\
\hline 40 & 89.25 & 81.75 & 82.5 & 87.5 & 81.75 & 89.25 & 85.5 \\
\hline 60 & 82.25 & 87.125 & 87.5 & 85.125 & 82.25 & 87.5 & 84.88 \\
\hline 70 & 89.375 & 92.05 & 89.625 & 91.8 & 89.375 & 92.05 & 90.71 \\
\hline 80 & 89.5 & 89.25 & 86.75 & 92 & 86.75 & 92 & 89.38 \\
\hline 90 & 77.75 & 85.775 & 80.25 & 83.275 & 77.75 & 85.775 & 81.76 \\
\hline 100 & 88.875 & 91.375 & 92.875 & 86.625 & 86.625 & 92.875 & 89.75 \\
\hline
\end{tabular}

Table3c: Uniformity coefficient of 8 Iph

\begin{tabular}{|l|l|l|l|l|l|l|l|}
\hline \multirow{2}{*}{$\begin{array}{l}\text { pressure } \\
(\mathrm{kPa})\end{array}$} & \multicolumn{7}{|c|}{ uniformity coefficient $(\mathrm{Cu}) \%$} \\
\cline { 2 - 8 } & 1 & 2 & 3 & 4 & Min & Max & Average \\
\hline 20 & 66.38 & 68.63 & 70.13 & 63.75 & 63.75 & 70.13 & 66.94 \\
\hline 30 & 65.5 & 73.25 & 72.625 & 66.125 & 65.5 & 73.25 & 69.38 \\
\hline 40 & 70.788 & 77.31 & 75.1 & 77.5625 & 70.788 & 77.5625 & 74.18 \\
\hline 60 & 79.31 & 78.13 & 79.25 & 78.19 & 78.13 & 79.31 & 78.72 \\
\hline 70 & 81.25 & 80.19 & 79.375 & 82.06 & 79.375 & 82.06 & 80.72 \\
\hline 80 & 87.69 & 89 & 85.1875 & 94 & 85.1875 & 94 & 89.59 \\
\hline 90 & 93.56 & 90.43 & 94.4375 & 89.55 & 89.55 & 94.4375 & 91.99 \\
\hline 100 & 94.38 & 91.2 & 97.3125 & 90.64 & 90.64 & 97.3125 & 93.98 \\
\hline
\end{tabular}

Table3d: Uniformity coefficient of 1.3 lph

\begin{tabular}{|l|l|l|l|l|l|l|l|}
\hline \multirow{2}{*}{$(\mathrm{kPa})$} & pressure & \multicolumn{7}{|c|}{ uniformity coefficient $(\mathrm{Cu}) \%$} \\
\cline { 2 - 8 } & 1 & 2 & 3 & 4 & Min & Max & Average \\
\hline 40 & 45.385 & 42.31 & 49.23 & 38.46 & 38.46 & 49.23 & 43.85 \\
\hline 50 & 47.308 & 45.77 & 53.08 & 40 & 40 & 53.08 & 46.54 \\
\hline 60 & 91.38 & 61.54 & 63.85 & 44.62 & 44.62 & 91.38 & 68 \\
\hline 70 & 59.231 & 92 & 85.08 & 66.15 & 59.231 & 92 & 75.62 \\
\hline 80 & 68.846 & 70.77 & 67.69 & 71.92 & 67.69 & 71.92 & 69.81 \\
\hline 90 & 96.4 & 84.08 & 75.62 & 86.31 & 75.62 & 96.4 & 86.01 \\
\hline 100 & 89.846 & 92 & 97.23 & 84.62 & 84.62 & 97.23 & 90.93 \\
\hline 110 & 81.615 & 89.77 & 84.15 & 87.23 & 81.615 & 89.77 & 85.69 \\
\hline
\end{tabular}


Table 4a. Emission uniformity of $2 \mathrm{lph}, 41 \mathrm{ph}$ and 8 lph capacity emitters

\begin{tabular}{|l|l|l|l|}
\hline \multirow{2}{*}{ Pressure (kPa) } & \multicolumn{3}{|c|}{ Emission uniformity , per cent } \\
\cline { 2 - 4 } & $\mathbf{2}$ Iph & $\mathbf{4}$ lph & $\mathbf{8}$ lph \\
\hline 20 & 73.83 & 61.54 & 78.17 \\
\hline 30 & 71.61 & 72.32 & 82.99 \\
\hline 40 & 86.37 & 69.69 & 79.78 \\
\hline 60 & 84.86 & 75.35 & 84.55 \\
\hline 70 & 66.76 & 84.73 & 88.97 \\
\hline 80 & 59.05 & 82.98 & 76.36 \\
\hline 90 & 68.62 & 68.36 & 88.31 \\
\hline 100 & 73.13 & 81.56 & 91.6 \\
\hline
\end{tabular}

Table4b: Emission uniformity for $1.3 \mathrm{lph}$ inline emitter

\begin{tabular}{|l|l|}
\hline Pressure $(\mathrm{kPa})$ & Emission Uniformity \\
\hline 40 & 66.25 \\
\hline 50 & 67.56 \\
\hline 60 & 77.54 \\
\hline 70 & 83.81 \\
\hline 80 & 83.49 \\
\hline 90 & 85.81 \\
\hline 100 & 83.91 \\
\hline 110 & 78.39 \\
\hline
\end{tabular}

Logarithmic relationships were developed between pressure and discharge for each of the online emitters of 2, 4 and $8 \mathrm{lph}$ and for inline emitter $1.3 \mathrm{lph}$ discharge ratings. The relations are shown in fig2.
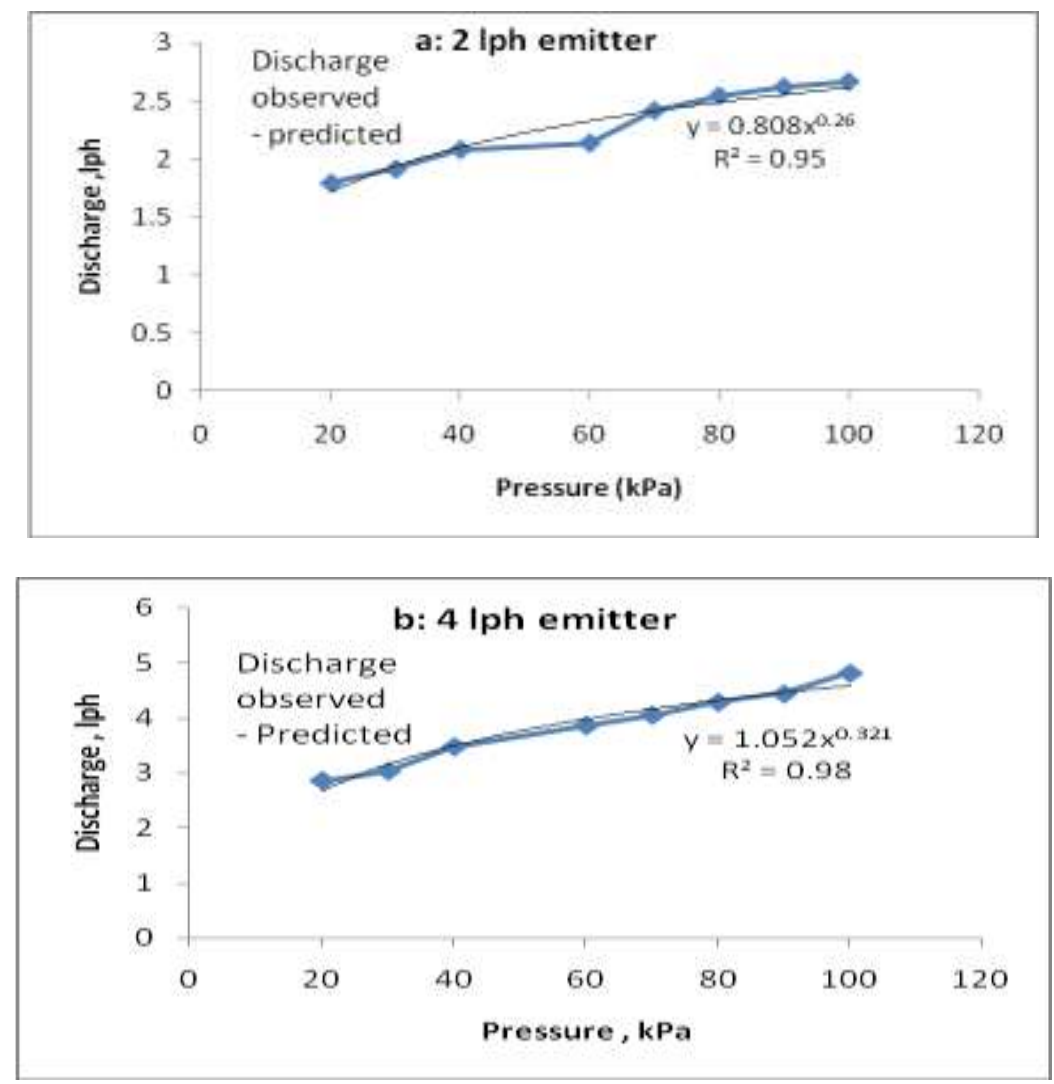

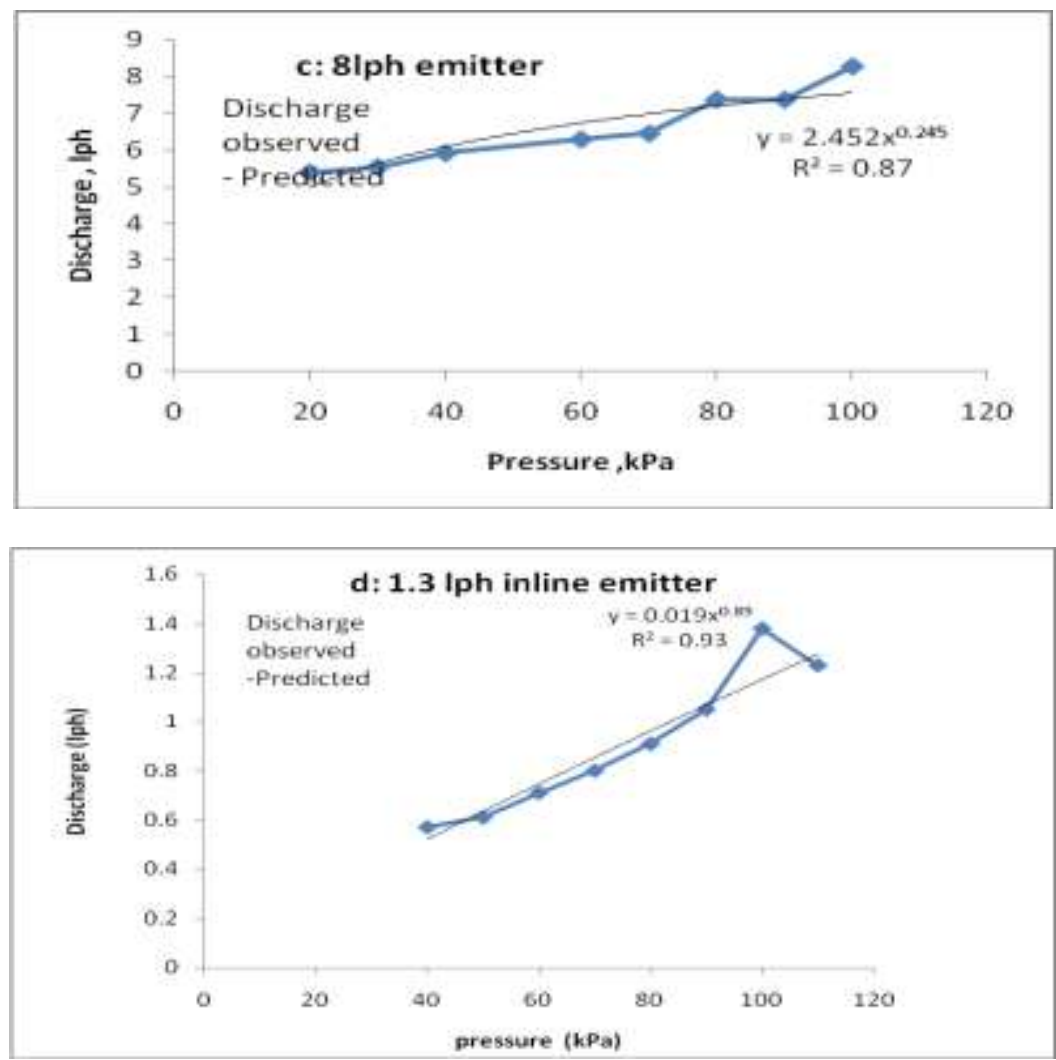

Fig: Relation between pressure and discharge of different emitters

\section{Conclusions}

Study revealed that for better discharges of online emitter s of 2, 4 and 8 lph rated discharge, operating pressure of 40, 70 and $100 \mathrm{kPa}$ rated discharge and inline emitter of $1.3 \mathrm{lph}$ rated discharge, operating pressure of $100 \mathrm{kPa}$ is required, respectively to achieve uniformity coefficient of more than $80 \%$. Manufacturing coefficients of variation were $0.651, .171$, and 0.101 for 2,4 and $8 \mathrm{lph}$ online-drip emitters and .128 for $1.3 \mathrm{lph}$ inline-drip emitter respectively. According to ASAE (1989) standards, the emitters were of good quality.

\section{References}

[1] Pandey, A.(2005) Hydraulic Performance of Drip Emitters under Laboratory Condition. J.Soil Wat. Conserv. India,4(3\&4)

[2] ASAE(1989) American Society of Agricultural Engineers. Design, installation and performance of trickle systems.EP405.1 St. Joseph, $M I$

[3] Christiansean,JE.(1942) Hydraulics of sprinkling systems for irrigation . Trans.ASCE. 107:221-239

[4] Kumar,A. (2001) State of art and research and development needs in micro irrigation . Proceeding of Manufacture.

[5] Meet cum Workshop on Automated Irrigation Equipment Testing Report No.CAIE/IDED/2002/277.pp. 51-57.

[6] Madramotto, C.A.(1988) Effect of pressure changes characteristics on the discharge characteristics of pressure compensating emitters. J.Agri. Engg. Res. 40: 159-164.Wu, I.P. and Giltin , H.M. (1977) Drip irrigation efficiency and schedules . Trans of the ASAE,26(I): $92-97$

[7] Satpute,G.V and Pandey,N.N. (1988) Effect of drip layout and planting geometry of tomato and cost of drip system. Proc . Agri.Engg. Conference Bangkok, Thailand;AIT(1992),773-781 pp. 